\title{
Correction: Queering the web archive: A xenofeminist approach to gender, function, language and culture in the London French Special Collection
}

\section{Saskia Huc-Hepher (D)}

Correction to: Humanities and Social Sciences Communications https://doi.org/10.1057/s41599-021-00967-8, published online 25 November 2021.

This article was incorrectly published with two supplementary files:

Marked-up version of the article for reviewers-resubmission 1

Marked-up version of the article for the Associate Editor-resubmission 2

These have now been removed from the published paper.

The online version of the paper and PDF have been corrected.

Published online: 07 December 2021

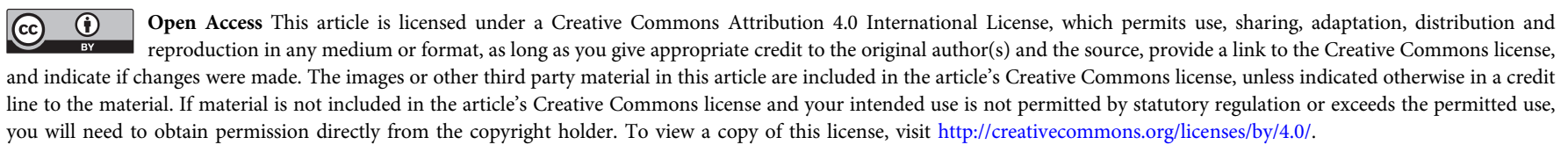

(C) The Author(s) 2021 